\title{
PERSPECTIVE
}

\section{The Fanconi road to cancer}

\author{
Alan D. D'Andrea ${ }^{1}$ \\ Department of Pediatric Oncology, Dana-Farber Cancer Institute, Harvard Medical School, \\ Boston, Massachusetts 02115, USA
}

Study of rare human genetic diseases often leads to significant advances in the understanding of cancer biology in general. Such is the case for Fanconi Anemia (FA), a rare cancer susceptibility syndrome with an incidence of only 1 in 300,000 live births. FA is an autosomal recessive disease characterized by chromosome instability, cellular hypersensitivity to DNA cross-linking agents such as Mitomycin $\mathrm{C}$ (MMC) and Cisplatin, and increased predisposition to cancers, mainly leukemias and squamous cell carcinomas of the head and neck or gynecologic system (Alter et al. 2003; Bagby 2003). Although the function of the seven cloned FA genes $(\mathrm{A}, \mathrm{C}, \mathrm{D} 1, \mathrm{D} 2$, $\mathrm{E}, \mathrm{F}$, and G) is largely unknown, the genes cooperate in a common cellular pathway, known as the FA/BRCA pathway (D'Andrea and Grompe 2003). The recent identification of the breast and ovarian cancer susceptibility gene, BRCA2, as the FANCD1 gene (Howlett et al. 2002) implicates the FA/BRCA pathway in homology-directed DNA repair (HDR), and suggests that disruption of the pathway may promote breast and ovarian cancer. In the current issue of Genes and Development, Houghtaling et al. (2003) analyze mice with a targeted deletion of one of the downstream FA genes-namely, Fancd2. Their analysis defines a role for the FA pathway in HDR and (at last) provides a molecular link between the FA pathway and epithelial cancers.

Several recent studies have defined molecular interactions among the FA proteins in the pathway (Fig. 1; for review, see D'Andrea and Grompe 2003). Five of the FA proteins (A, C, E, F, and G) form a nuclear complex (Garcia-Higuera et al. 1999; Medhurst et al. 2001) required for the activation (monoubiquitination) of the downstream FANCD2 protein (Garcia-Higuera et al. 2001). This FA protein complex either has intrinsic monoubiquitin ligase activity or it regulates a monoubiquitin ligase. Following DNA damage by cross-linking agents, FANCD2 is monoubiquitinated and targeted to chromatin-associated foci, where it interacts with the breast cancer protein, BRCA1 (Garcia-Higuera et al. 2001) and the MRE11/RAD50/NBS1 (M/R/N) complex (Nakanishi et al. 2002). Moreover, the BRCA1/BARD1 heterodimeric ubiquitin ligase complex (Brzovic et al. 2001) is required for the efficient assembly of these foci (A. D'Andrea, unpubl.). Disruption of the FA/BRCA pathway results in

${ }^{1}$ E-MAIL alan_dandrea@dfci.harvard.edu; FAX (617) 632-5757. Article published online ahead of print. Article and publication date are at http://www.genesdev.org/cgi/doi/10.1101/gad.1128303. chromosome instability, DNA cross-linker hypersensitivity, and the common clinical features of FA.

FA-D1 patients have biallelic mutations in FANCD1/ BRCA2 (Howlett et al. 2002; Stewart and Elledge 2002). BRCA2 functions further downstream in the FA/BRCA pathway, and, unlike other FA proteins, appears to play a more direct role in DNA repair. BRCA2 binds to singleand double-strand DNA (Yang et al. 2002) and binds to RAD51 through its BRC regions (Marmorstein et al. 1998). Moreover BRCA2 regulates the activity of RAD51, by controlling nucleoprotein filament formation (Davies et al. 2001). Loading of RAD51 on singlestrand DNA by BRCA2 is required for the early events in homologous recombination repair, such as strand invasion. Biallelic inactivation of $B R C A 2$ results in a cellular defect in HDR (Moynahan et al. 2001). Perhaps not surprisingly, biallelic null mutations in BRCA2 in humans or Brca2 in mice result in embryonic lethality. Cells derived from FA-D1 patients, however, have hypomorphic alleles of $F A N C D 1 / B R C A 2$, expressing truncated BRCA2 polypeptides with partial activity (Howlett et al. 2002). These FA-D1 individuals survive gestation but die in early childhood.

\section{Murine knockout models for FA genes}

To date, murine knockout models of several Fanc genes, including Fancc (Chen et al. 1996; Whitney et al. 1996), Fanca (Rio et al. 2002), and Fancg (Yang et al. 2001) have been generated. Although these FA mice exhibit some phenotype features of human FA patients (i.e., chromosome instability, defective germ cell development), they do not spontaneously develop anemia or cancer. The phenotypes of these knockout mice are essentially indistinguishable (Noll et al. 2002), consistent with a model (Fig. 1) in which the FA protein complex components cooperate to perform a common function. Because of the more downstream role of Fancd2 in the FA pathway, Houghtaling et al. (2003) postulated a more critical role of Fancd2 in murine development and carcinogenesis. As predicted, the Fancd2 $2^{-/-}$mice do indeed exhibit a more severe phenotype.

Specifically, the Fancd2 $2^{-/-}$mice exhibit micropthalmia (small eyes), perinatal lethality, and more severe hypogonadism than the Fanca-, Fancg-, or Fancc-deficient mice. Strikingly, the Fancd2-deficient mice have an increased incidence of epithelial cancers (i.e., breast, ovarian, and liver cancers), similar to the tumor spectrum 
Figure 1. Cooperative interaction of the FA proteins and BRCA proteins in a common pathway. The FA proteins $(\mathrm{A}, \mathrm{C}, \mathrm{E}, \mathrm{F}, \mathrm{G})$ are assembled in a nuclear protein complex. Recent studies have indicated that the Bloom's helicase, BLM, is also a subunit of the complex. The FA complex is required for the monoubiquitination of the downstream FANCD2 protein. The FA monoubiquitination ligase activity of the FA complex is activated by DNA damage, perhaps through the activity of an upstream "sensor" kinase. Monoubiquitinated FANCD2 is targeted to chromatin-associated nuclear foci where it assembles with the breast cancer susceptibility proteins, BRCA1 and BRCA2. These nuclear foci also contain the RAD51 protein and the MRE11/RAD50/NBS1 (M/R/N) complex. The ubiquitin ligase (BRCA1/BARD1) heterodimer is required for the efficient assembly of these chromatin foci; accordingly, $B R C A 1^{-/-}$tumor cells have decreased FANCD2 nuclear foci. BRCA2 interacts with RAD51, and these proteins are required for homologydirected DNA repair (HDR). Disruption of genes in this pathway results in chromosome instability, cellular hypersensitivity to DNA cross-linking agents, and a propensity to cancer progression.

observed in Brca2 hypomorphic mice (Tutt et al. 2001; McAllister et al. 2002). Taken together, the phenotype of the Fancd2-deficient mice provides an important experimental verification of the sequence of molecular events in the FA pathway (Fig. 1), with Fancd2 and Brca2/ Fancd1 playing a more critical downstream role.

\section{Role of the FA/BRCA pathway in homologous recombination repair}

Increasing evidence supports a role for the FA/BRCA pathway in HDR. First, FA cells are hypersensitive to DNA cross-linking agents, similar to the cellular phenotype observed in HDR-defective $\mathrm{CHO}$ cells containing mutations in the DNA recombination genes XRCC3 (Pierce et al. 1999) or BRCA2 (Kraakman-van der Zwet et al. 2002). Second, activated (monoubiquitinated) FANCD2 forms nuclear foci with BRCA1 and RAD51 during $S$ phase, a cell-cycle stage in which HDR between sister chromatids is known to occur (Taniguchi et al. 2002). Third, FA cells exhibit an increased mutation frequency, based on the high number of spontaneous mutations observed in the reporter gene, HPGRT gene. Moreover, the abnormal spectrum of HGPRT mutations observed in FA cells is consistent with abnormal HDR (Papadopoulo et al. 1990). Finally, the BLM helicase, another protein identified as a component of the FA complex (A/C/E/F/G complex; Meetei et al. 2003), has been implicated in HDR activities such as telomere length maintenance (Stavropoulos et al. 2002). Although BLM is not required for the monoubiquitination of FANCD2, its presence in the complex suggests that BLM may recruit the FA complex to chromatin.

Analysis of the new Fancd2-deficient mice provides additional clues to the function of the FA pathway in HDR (Houghtaling et al. 2003). Spermatocytes isolated from the Fancd2-deficient mice exhibited abnormal pair- ing of homologous chromosomes during the meiotic pachytene stage. Similarly, somatic cells isolated from these mice exhibited spontaneous and DNA damage-inducible chromosome quadriradial forms, composed of mispaired nonhomologous chromosomes. These observations raise the interesting possibility that the FA/BRCA pathway regulates the fidelity of homologous chromosome or sister chromatid pairing, whereas the downstream BRCA2/RAD51 elements mediate the more direct events in HDR. Consistent with this view, human FA fibroblasts which have biallelic mutations in an upstream FA gene, such as FANCA or FANCG, have only a minor (twofold) defect in HDR (A. D'Andrea, unpubl.), compared with the eightfold defect observed in BRCA1 $1^{--}$cells (Moynahan et

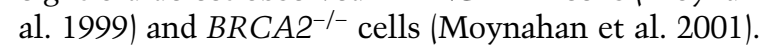

Several questions regarding the role of the FA/BRCA pathway in HDR remain unanswered. Are Fancd2-deficient MEF or ES cells specifically defective in HDR? Are other DNA repair mechanisms also defective? A systematic analysis of Fancd2-deficient cells, using plasmidbased recombination substrates, will be a logical starting point for addressing these questions (Pierce et al. 1999; Tutt et al. 2001).

Another critical unanswered question is the molecular basis of the selective DNA cross-linker sensitivity of Fancd2-deficient cells. In general, FA cells are hypersensitive to MMC but exhibit normal resistance to ionizing radiation (IR). Both MMC and IR generate double-strand DNA breaks (dsbs; D'Andrea and Grompe 2003), lesions normally repaired either by HDR or nonhomologous end joining (NHEJ). The selective defect in MMC cross-link repair in FA cells suggests a defect in the ability to sense DNA cross-links or to process cross-links into dsbs. On the one hand, the FA protein complex may function to sense DNA damage. For instance, the FA complex, containing the BLM helicase component, may detect and bind to a DNA cross-link, leading to activation of 
FANCD2 monoubiquitination and a subsequent repair process (Fig. 1). On the other hand, the FA pathway may function further downstream to process the DNA damage. The monoubiqutinated FANCD2 protein may cooperate with BRCA2 and RAD51 to repair DNA containing cross-links. Despite the rapid progress in the FA/BRCA field, including gene cloning, the elucidation of biochemical events in the pathway, and successful mouse modeling, no consistent explanation has yet emerged for the selective cross-linker hypersensitivity of FA cells.

\section{Disruption of the FA/BRCA pathway during epithelial cancer progression}

The most important finding of Houghtaling et al. (2003) is the predisposition of Fancd2-deficient mice to epithelial cancers-mainly breast, ovarian, and liver cancers. Human cancers are usually epithelial in origin, and develop with advancing age. Human tumors often display complex cytogenetic profiles, including aneuploidy and chromosome structural abnormalities. As most genetic murine models described to date develop soft tissue sarcomas and lymphomas, these models bear little relevance to the common epithelial cancers of humans. The new Fancd2-deficient murine model, along with the Brca2-deficient model (McAllister et al. 2002) and the telomerase-deficient model (Artandi et al. 2000) which also develop epithelial cancers, may therefore be more relevant to the study of many human cancers.

The development of epithelial cancers in the Fancd2deficient mice has several important implications. First, the findings strongly support a genetic interaction between Fancd2 and Brca2, consistent with the pathway described in Figure 1. Biochemical evidence further supports this genetic interaction, as the activated (monoubiquitinated) form of FANCD2 colocalizes with BRCA2 in chromatin, and a biochemical complex containing these proteins has been partially purified (A. D'Andrea, unpubl.).

Second, the findings suggest a possible interaction between the FA/BRCA pathway and telomere length maintenance. Consistent with this notion, FA cells have accelerated telomere shortening (Callen et al. 2002). Future studies, such as the crossing of Fanc-deficient and telomerase-deficient mice, are needed to determine whether activated FANCD2 functions to maintain telomere length, perhaps via HDR. Loss of telomerase activity or loss of activated FANCD2 protein may contribute to telomere attrition, end-to-end chromosome fusion, and epithelial carcinogenesis.

Third, the gradual progression of epithelial cancers in the Fancd2-deficient mice will allow the systematic assessment of relevant chromosome breaks, deletions, and insertions in the tumors. In this way, the development of the murine epithelial cancers may mimic epithelial cancer progression in humans. Tumor cell lines derived from the Fancd2-deficient mice should be examined by spectral karyotype analysis (SKY), in order to determine the frequency of site-specific chromosome translocations and amplifications. Tumor-derived genomic DNA should be analyzed by array comparative genomic hy- bridization (O'Hagan et al. 2002), to detect amplifications and deletions of cancer-relevant loci, specifically in regions syntenic to human epithelial cancer hotspots.

The Fancd2-deficient mice may elucidate other aspects of epithelial cancer development. The generation of Fancd2 $2^{-1-}$, p53-/- double-knockout mice will allow the assessment of a genetic interaction between the FA/BRCA pathway and $p 53$. Perhaps the double-knockout mice will have enhanced tumorigenesis, with shortened tumor latency and a different tumor spectrum. Similarly, it will be important to determine whether restoration of the FA pathway, perhaps by compensatory mutations, results during the progression of epithelial cancer in these animals. Recent studies indicate that tumors from FA patients may result, at least in part, from somatic reversion, restoration of the FA pathway, and restoration of genomic stability and drug resistance (Ikeda et al. 2003).

In addition to Houghtaling et al. (2003), other recent studies support a pivotal role of the FA/BRCA pathway in epithelial cancer progression. Taniguchi et al. (2003) demonstrated that at least $18 \%$ of primary ovarian epithelial cancers have a disruption of the FA/BRCA pathway, perhaps accounting for the well known chromosome instability and cisplatin hypersensitivity of these tumors. Disruption of the pathway results from the methylation and silencing of one of the upstream FA genes, FANCF. Also, Van Der Heijden et al. (2003) recently suggested that germline FANCG or FANCC mutations may account for the chromosome instability and cross-linker sensitivity of tumors from some patients with inherited pancreatic cancer. Tumors from such patients are hemizygous for FANCG; they contain an inherited (mutant) FANCG allele, whereas the wild-type allele has been deleted.

These studies indicate that disruption of the FA/BRCA pathway, by germline mutations, somatic mutations, or epigenetic silencing of FANC genes, may contribute to epithelial cancer progression. Transient inactivation of the FA/BRCA pathway may result in chromosome instability, the activation of new oncogenes, and the inactivation of tumor suppressors, thus enhancing the malignant phenotype. Restoration of the FA/BRCA pathway, by compensatory mutations later in the evolution of the cancer, may restore genomic stability, may provide an alternative mechanism for telomere length maintenance (ALT), and may promote chemotherapy resistance. The new finding of epithelial cancers in Fancd2-deficient mice will no doubt fuel new efforts to examine the integrity of the FA/BRCA pathway in other human cancers, especially those cancers with chromosome breakage and DNA cross-linker hypersensitivity.

\section{References}

Alter, B.P., Greene, M.H., Velazquez, I., and Rosenberg, P.S 2003. Cancer in Fanconi anemia. Blood 101: 2072.

Artandi, S.E., Chang, S., Lee, S.L., Alson, S., Gottlieb, G.J., Chin, L., and DePinho, R.A. 2000. Telomere dysfunction promotes nonreciprocal translocations and epithelial cancers in mice. Nature 406: 641-645. 
Bagby Jr., G.C. 2003. Genetic basis of Fanconi anemia. Curr. Opin. Hematol. 10: 68-76.

Brzovic, P.S., Rajagopal, P., Hoyt, D.W., King, M.C., and Klevit, R.E. 2001. Structure of a BRCA1-BARD1 heterodimeric RING-RING complex. Nat. Struct. Biol. 8: 833-837.

Callen, E., Samper, E., Ramirez, M.J., Creus, A., Marcos, R., Ortega, J.J., Olive, T., Badell, I., Blasco, M.A., and Surralles, J. 2002. Breaks at telomeres and TRF2-independent end fusions in Fanconi anemia. Hum. Mol. Genet. 11: 439-444.

Chen, M., Tomkins, D.J., Auerbach, W., McKerlie, C., Youssoufian, H., Liu, L., Gan, O., Carreau, M., Auerbach, A., Groves, T., et al. 1996. Inactivation of Fac in mice produces inducible chromosomal instability and reduced fertility reminiscent of Fanconi anaemia. Nat. Genet. 12: 448-451.

D'Andrea, A.D. and Grompe, M. 2003. The Fanconi anaemia/ BRCA pathway. Nat. Rev. Cancer 3: 23-34.

Davies, A.A., Masson, J.Y., McIlwraith, M.J., Stasiak, A.Z., Stasiak, A., Venkitaraman, A.R., and West, S.C. 2001. Role of BRCA2 in control of the RAD51 recombination and DNA repair protein. Mol. Cell 7: 273-282.

Garcia-Higuera, I., Kuang, Y., Naf, D., Wasik, J., and D'Andrea, A.D. 1999. Fanconi anemia proteins FANCA, FANCC, and FANCG/XRCC9 interact in a functional nuclear complex. Mol. Cell. Biol. 19: 4866-4873.

Garcia-Higuera, I., Taniguchi, T., Ganesan, S., Meyn, M.S., Timmers, C., Hejna, J., Grompe, M., and D'Andrea, A.D. 2001. Interaction of the Fanconi anemia proteins and BRCA1 in a common pathway. Mol. Cell 7: 249-262.

Houghtaling, S., Timmers, C., Noll, M., Finegold, M.J., Jones, S.N., Meyn, M.S., and Grompe, M. 2003. Epithelial cancer in Fanconi anemia complementation group D2 (Fancd2) knockout mice. Genes \& Dev. (this issue).

Howlett, N.G., Taniguchi, T., Olson, S., Cox, B., Waisfisz, Q., De Die-Smulders, C., Persky, N., Grompe, M., Joenje, H., Pals, G., et al. 2002. Biallelic inactivation of BRCA2 in Fanconi anemia. Science 297: 606-609.

Ikeda, H., Matsushita, M., Waisfisz, Q., Kinoshita, A., Oostra, A.B., Nieuwint, A.W., De Winter, J.P., Hoatlin, M.E., Kawai, Y., Sasaki, M.S., et al. 2003. Genetic reversion in an acute myelogenous leukemia cell line from a Fanconi anemia patient with biallelic mutations in BRCA2. Cancer Res. 63: 2688-2694.

Kraakman-van der Zwet, M., Overkamp, W.J., van Lange, R.E., Essers, J., van Duijn-Goedhart, A., Wiggers, I., Swaminathan, S., van Buul, P.P., Errami, A., Tan, R.T., et al. 2002. Brca2 (XRCC11) deficiency results in radioresistant DNA synthesis and a higher frequency of spontaneous deletions. Mol. Cell. Biol. 22: 669-679.

Marmorstein, L.Y., Ouchi, T., and Aaronson, S.A. 1998. The BRCA2 gene product functionally interacts with p53 and RAD51. Proc. Natl. Acad. Sci. 95: 13869-13874.

McAllister, K.A., Bennett, L.M., Houle, C.D., Ward, T., Malphurs, J., Collins, N.K., Cachafeiro, C., Haseman, J., Goulding, E.H., Bunch, D., et al. 2002. Cancer susceptibility of mice with a homozygous deletion in the $\mathrm{COOH}$-terminal domain of the Brca2 gene. Cancer Res. 62: 990-994.

Medhurst, A.L., Huber, P.A., Waisfisz, Q., de Winter, J.P., and Mathew, C.G. 2001. Direct interactions of the five known Fanconi anaemia proteins suggest a common functional pathway. Hum. Mol. Genet. 10: 423-429.

Meetei, A.R., Sechi, S., Wallisch, M., Yang, D., Young, M.K., Joenje, H., Hoatlin, M.E., and Wang, W. 2003. A multiprotein nuclear complex connects Fanconi anemia and Bloom syndrome. Mol. Cell Biol. 23: 3417-3426.

Moynahan, M.E., Chiu, J.W., Koller, B.H., and Jasin, M. 1999. Brcal controls homology-directed DNA repair. Mol. Cell
4: $511-518$.

Moynahan, M.E., Pierce, A.J., and Jasin, M. 2001. BRCA2 is required for homology-directed repair of chromosomal breaks. Mol. Cell 7: 263-272.

Nakanishi, K., Taniguchi, T., Ranganathan, V., New, H.V., Moreau, L.A., Stotsky, M., Mathew, C.G., Kastan, M.B., Weaver, D.T., and D'Andrea, A.D. 2002. Interaction of FANCD2 and NBS1 in the DNA damage response. Nat. Cell Biol. 4: 913-920.

Noll, M., Battaile, K.P., Bateman, R., Lax, T.P., Rathbun, K., Reifsteck, C., Bagby, G., Finegold, M., Olson, S., and Grompe, M. 2002. Fanconi anemia group A and C doublemutant mice. Functional evidence for a multi-protein Fanconi anemia complex. Exp. Hematol. 30: 679-688.

O'Hagan, R.C., Chang, S., Maser, R.S., Mohan, R., Artandi, S.E., Chin, L., and DePinho, R.A. 2002. Telomere dysfunction provokes regional amplification and deletion in cancer genomes. Cancer Cell 2: 149-155.

Papadopoulo, D., Guillouf, C., Mohrenweiser, H., and Moustacchi, E. 1990. Hypomutability in Fanconi anemia cells is associated with increased deletion frequency at the HPRT locus. Proc. Natl. Acad. Sci. 87: 8383-8387.

Pierce, A.J., Johnson, R.D., Thompson, L.H., and Jasin, M. 1999. XRCC3 promotes homology-directed repair of DNA damage in mammalian cells. Genes \& Dev 13: 2633-2638.

Rio, P., Segovia, J.C., Hanenberg, H., Casado, J.A., Martinez, J., Gottsche, K., Cheng, N.C., Van De Vrugt, H.J., Arwert, F., Joenje, H., et al. 2002. In vitro phenotypic correction of hematopoietic progenitors from Fanconi anemia group A knockout mice. Blood 100: 2032-2039.

Stavropoulos, D.J., Bradshaw, P.S., Li, X., Pasic, I., Truong, K., Ikura, M., Ungrin, M., and Meyn, M.S. 2002. The Bloom syndrome helicase BLM interacts with TRF2 in ALT cells and promotes telomeric DNA synthesis. Hum. Mol. Genet. 11: $3135-3144$.

Stewart, G. and Elledge, S.J. 2002. The two faces of BRCA2, a FANCtastic discovery. Mol. Cell 10: 2-4.

Taniguchi, T., Garcia-Higuera, I., Andreassen, P.R., Gregory, R.C., Grompe, M., and D'Andrea, A.D. 2002. S-phase-specific interaction of the Fanconi anemia protein, FANCD2, with BRCA1 and RAD51. Blood 100: 2414-2420.

Taniguchi, T., Tischkowitz, M., Ameziane, N., Hodgson, S.V., Mathew, C.G., Joenje, H., Mok, S.C., and D'Andrea, A.D. 2003. Disruption of the Fanconi anemia-BRCA pathway in cisplatin-sensitive ovarian tumors. Nat. Med. 9: 568-574.

Tutt, A., Bertwistle, D., Valentine, J., Gabriel, A., Swift, S., Ross, G., Griffin, C., Thacker, J., and Ashworth, A. 2001. Mutation in Brca2 stimulates error-prone homology-directed repair of DNA double-strand breaks occurring between repeated sequences. EMBO J. 20: 4704-4716.

Van Der Heijden, M.S., Yeo, C.J., Hruban, R.H., and Kern, S.E. 2003. Fanconi anemia gene mutations in Young-onset pancreatic cancer. Cancer Res. 63: 2585-2588.

Whitney, M.A., Royle, G., Low, M.J., Kelly, M.A., Axthelm, M.K., Reifsteck, C., Olson, S., Braun, R.E., Heinrich, M.C., Rathbun, R.K., et al. 1996. Germ cell defects and hematopoietic hypersensitivity to $\gamma$-interferon in mice with a targeted disruption of the Fanconi anemia C gene. Blood 88: 49-58.

Yang, H., Jeffrey, P.D., Miller, J., Kinnucan, E., Sun, Y., Thoma, N.H., Zheng, N., Chen, P.L., Lee, W.H., and Pavletich, N.P. 2002. BRCA2 function in DNA binding and recombination from a BRCA2-DSS1-ssDNA structure. Science 297: 1837-1848.

Yang, Y., Kuang, Y., De Oca, R.M., Hays, T., Moreau, L., Lu, N., Seed, B., and D'Andrea, A.D. 2001. Targeted disruption of the murine Fanconi anemia gene, Fancg/Xrcc9. Blood 98: $3435-3440$. 


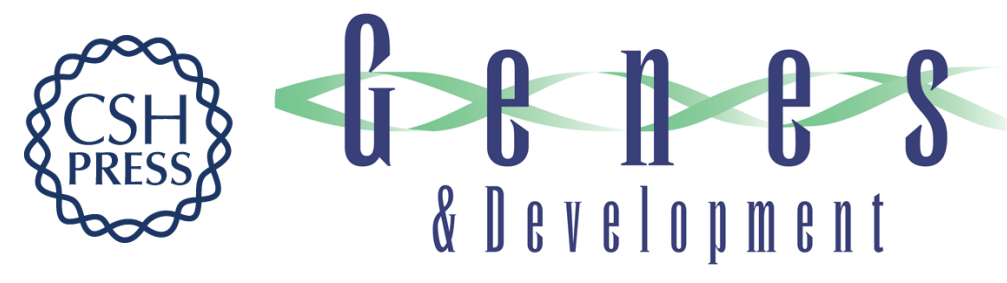

\section{The Fanconi road to cancer}

Alan D. D'Andrea

Genes Dev. 2003, 17:

Access the most recent version at doi:10.1101/gad.1128303

References This article cites 34 articles, 17 of which can be accessed free at: http://genesdev.cshlp.org/content/17/16/1933.full.html\#ref-list-1

License

Email Alerting Receive free email alerts when new articles cite this article - sign up in the box at the top Service right corner of the article or click here.

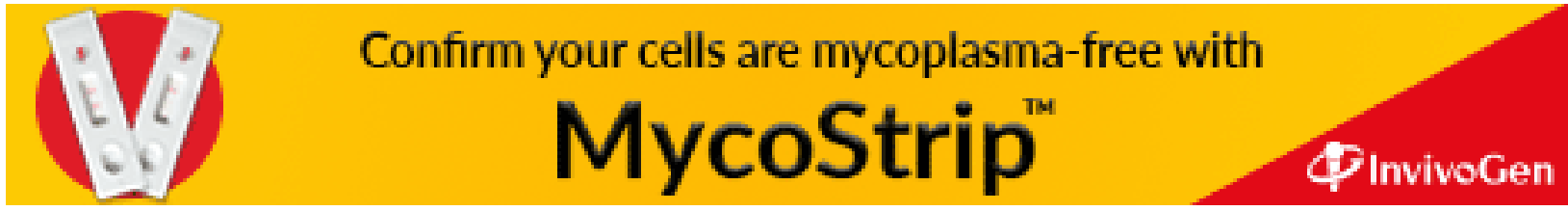

